\title{
Estudio de la evolución y tendencias de la comunicación estratégica integral
} Study of the Evolution and Trends of the Integrated Strategic communication

Celia Rangel Pérez. Doctora ESIC Business \& Marketing School celia.rangel@esic.edu

María José Carretero Velasco. Doctoranda ESIC Business \& Marketing School

mariajose.carretero@esic.edu
Rangel Pérez, C. y Carretero Velasco, Ma. J. (2017)

Estudio de la evolución y tendencias de la comunicación estratégica integral

Revista Internacional de Investigación en Comunicación aDResearch ESIC. № 16 Vol 16

Segundo semestre, julio-diciembre 2017 · Págs. 8 a 33 DOI: 16.7263/ADRESIC.016.001 


\section{Clasificación JEL:}

M37

Palabras clave:

Estrategia,

omnicanal,

campaña integrada,

nuevo modelo,

comunicación
El artículo parte de las conclusiones del estudio de las campañas integrales premiadas del Festival Iberoamericano de la Comunicación Publicitaria, El Sol, 2014. Allí se ve cómo se rompen barreras entre diferentes disciplinas de comunicación, buscando interactividad fuera y dentro de la red, y una nueva manera de relacionarse con los consumidores. Detrás, el interés de las organizaciones por crear marcas relevantes para sus stakeholders, que consigan objetivos empresariales. El trabajo busca confirmar que estamos ante un nuevo modelo de comunicación omnicanal, con tres pilares estratégicos: combinación de soportes o acciones, estudio de los públicos y objetivos claros. Todos anclados en una estrategia de comunicación coherente, que persiga la eficacia de la comunicación y la medición de resultados. Se trata de combinar los mejores canales para racionalizar la inversión y concentrar esfuerzos, donde de verdad estén los públicos objetivos, reforzando los puntos de contacto. El fin sigue siendo comunicar un mensaje claro que conecte. De ahí que, para investigar dicho modelo, se realiza un análisis, partiendo de las campañas estudiadas anteriormente, ampliando la muestra a las campañas premiadas en el Festival de Cannes Lions 2015, sección Titanium and Integrated. Se aplicará igual metodología: análisis cuantitativo, identificando las herramientas más utilizadas, y cualitativo, detectando funciones y similitudes de cada elemento. Los resultados permitirán observar un nuevo modelo de comunicación estratégico que, poco a poco, van adoptando anunciantes y agencias, en más países cada vez.

\section{ABSTRACT}

\section{JEL Classification: \\ M37}

Key words:

Strategy, omni-channel, integrated campaign, new model, communication
This article is based on the conclusions drawn from the study of integrated campaigns at El Sol Iberoamerican Advertising Festival of 2014. The latter established that barriers among the different communication tools dissipate in search of interactivity off and online and a new way to relate to consumers. Companies want to create not only relevant brands for their stakeholders, but also profitable ones. This article confirms that we are facing a new omni-channel communication model based on three strategic pillars: combination of advertising holders or activities, a target study and clear objectives. The three of them must be anchored to a coherent communication strategy; they must pursue communication efficiency and results measurement. There is no need to combine many channels, but the best communication activities must be chosen to rationalize investments, concentrate efforts where the target of the brand is and reinforce brand touch points. The aim is still to transmit a clear message which connects with consumers. To study the new omni-channel communication, we follow the former analysis and expand the El Sol sample to those campaigns awarded at Cannes Lions Festival 2015, within the Titanium and Integrated section. The same methodology will be applied: a quantitative analysis will be made to identify the most used tools; and a qualitative one, to study the functions and similarities of each communication tool. In view of all this, it is clear that a new communication model is slowly but surely being used by agencies and organizations abroad. 


\section{Introducción}

Agencias y anunciantes vivimos una época tan apasionante como convulsa (Aguilera Moyano et al., 2016). Desde el punto de vista del anunciante, se pide a los responsables de Marketing y Comunicación obtener los mismos resultados que con presupuestos y recursos de años previos a la crisis; la presión por la medición y el retorno de la inversión, cada vez es mayor. La segmentación de disciplinas en agencias muy especializadas, lleva a que la gestión de la comunicación comercial, entendida como un todo, sea cada vez más complicada, desde el anunciante. El foco en el corto plazo de la dirección de muchos de ellos, obliga a tomar decisiones tácticas, sin pensar en objetivos reputacionales o en una coherencia comunicativa (Mayorga, 2016). Además, se echa en falta a profesionales que, sea cual sea su especialidad, sepan ayudar a los clientes en la gestión global de la comunicación comercial (Nyilasy y Reid, 2007). Por otra parte, desde el punto de vista de la agencia, fruto de la crisis y de la supervivencia, ha surgido una mayor especialización (Ambwan et al. 2011). Las grandes agencias con metodologías de multinacionales conviven con pequeñas agencias independientes. Muchos de los grandes expertos de grandes agencias son hoy consultores independientes que dan servicio a antiguos clientes. La crisis ha obligado a muchas agencias a contratar gran número de profesionales noveles (Castellanos, 2015) sin apenas experiencia.

El consumidor vive ajeno a la maquinaria que trata de llegar a él eficazmente. Y está acostumbrado al constante bombardeo publicitario dentro y fuera de casa. Tanto, que a veces le resulta ajeno o incluso puede evitar la publicidad en ciertos soportes. Internet, ese reducto publicitario que parecía la panacea, también se está viendo sacudido por las aplicaciones que bloquean la publicidad (Busch, 2015) en soportes móviles u ordenador. De ahí que agencias y anunciantes estén continuamente innovando en soportes, mensajes y creatividad, para llegar a un consumidor saturado, de forma única y relevante, con campañas integradas que pueden estar presentes en todos los puntos de contacto entre consumidor y marca, por muy diversos que sean, y que, sobre todo, no son lo que entendíamos tradicionalmente como publicidad.

La presente investigación surge tras la realización de un estudio donde se analizaron las campañas integradas del Festival de publicidad El Sol de 2014 (Carretero, Rangel, 2017). Una de las principales conclusiones fue que estábamos ante un posible nuevo modelo de comunicación omnicanal, basado en la técnica de la repetición, que facilita la aprehensión del mensaje por parte del cerebro (Damasio, 2010). Dicho modelo podría estar anclado en tres pilares: combinación de diferentes soportes o acciones, estudio de los públicos de la marca y planteamiento de objetivos claros. Para poder afirmar que estamos ante un nuevo modelo, de forma rotunda, queremos confirmar las conclusiones de la primera investigación con la presente, ahora en un ámbito aún más internacional.

\section{Objetivos y metodología}

Para comprobar si estamos ante un cambio de paradigma en la publicidad, se plantean tres objetivos, basados en la investigación previamente mencionada:

- Definir los elementos que caracterizan a las campañas integradas.

- Analizar los mecanismos de integración de diferentes áreas de marketing para la realización de las campañas. 
- Estudiar si se están implementando nuevos elementos de comunicación para crear campañas atractivas para el consumidor.

Para poder contrastar los datos de un modo preciso, la metodología será la utilizada en la investigación mencionada de las campañas del Festival el Sol. En este caso, la muestra está compuesta por las campañas ganadoras de premio en el Festival Cannes Lions en 2015, sección Titanium and Integrated (las últimas disponibles en el momento de realizar el presente estudio). De cada campaña de la muestra, se realizará un análisis del mensaje, se enumerarán los soportes y tipos de acciones utilizados y se detallarán los resultados obtenidos. A partir de ahí, se realizará un análisis cuantitativo, para extraer las acciones más empleadas, para buscar mayor impacto en el consumidor, sin valorar creatividad y/o originalidad del mensaje, sino solo herramientas de comunicación utilizadas. Una vez identificados los elementos de comunicación, se realizará un análisis cualitativo con dos partes: estudio individual, analizando la función de cada elemento en la campaña; y estudio de las campañas en su conjunto, para valorar los elementos comunes y comprobar si su función es similar en ellas.

\section{Investigación de las campañas Titanium e Integrated del Festival Cannes Lions en 2015}

En las siguientes fichas se resume la principal información de las campañas estudiadas: mensaje, soporte y acciones, y resultados.

\section{Pedidos Emoji. Domino's Pizza (Brand Buffet, 2015a).

\begin{tabular}{|l|l|}
\hline Mensaje & $\begin{array}{l}\text { EE.UU. Primera empresa con pedidos con emojis. Lanzó un innovador método, a través de } \\
\text { un tweet que citaba a Domino's, con un emoji de pizza; o enviando a @DominosPizza el } \\
\text { mensaje \#EasyOrder. Los usuarios recibían confirmación en la red. Debían registrarse en la } \\
\text { página, detallar el pedido y asociarlo a la cuenta de Twitter, guardando el pedido favorito. }\end{array}$ \\
\hline Soportes y acciones & RR.SS., web y RR.PP. \\
\hline Resultados & $\begin{array}{l}\text { Gran repercusión en medios. Posicionamiento de marca innovador: primera empresa } \\
\text { mundial en realizarlo. Primer día: } 500 \text { pedidos Emoji. }\end{array}$ \\
\hline
\end{tabular}

Fuente: elaboración propia.

2. \#re2pect. Michel Jordan - Nike (Videos y Punto, 2015).

\begin{tabular}{|c|c|}
\hline Mensaje & $\begin{array}{l}\text { Colección especial, para la despedida de Derek Jeter, legendario capitán, n } 2 \text { de los New } \\
\text { York Yankees de beisbol (uno de los eventos deportivos más mediáticos). Se rindió un ho- } \\
\text { menaje con un spot, de famosos y desconocidos, hasta de equipos rivales, que levantaban } \\
\text { su gorra, como respeto hacia él. Se invitaba a la audiencia a participar con un hashtag en } \\
\text { Twitter, enviando su saludo, y a ver la colección. }\end{array}$ \\
\hline Soportes y acciones & Spot de TV, RR.SS., publicidad exterior, RR.PP. y acción en el estadio. \\
\hline Resultados & $\begin{array}{l}\text { Entre todas las marcas que le homenajearon, fue la más notoria. La calle recogió el gesto y } \\
\text { lo hizo suyo (realizándolo hasta los astronautas); así como medios y periodistas. }\end{array}$ \\
\hline
\end{tabular}




\section{Clever Buoy [boya inteligente]. Optus (StarterDaily, 2015).}

\begin{tabular}{|l|l|}
\hline Mensaje & $\begin{array}{l}\text { Compañía australiana de telecomunicaciones. Transmitió que su red cubría el continente, } \\
\text { con valor añadido. Diseñó boyas que detectaban tiburones, rodeó la costa, enviando alertas. } \\
\text { Dio respuesta a este peligro, donde más muertes causan, evitando daños a personas y tibu- } \\
\text { rones. Solución económica, eficiente y respetuosa con la vida. }\end{array}$ \\
\hline Soportes y acciones & RR.SS., RR.PP. y acción ad hoc. \\
\hline Resultados & $\begin{array}{l}\text { 84\% de incremento del sentimiento positivo de sus clientes (recogido en RR.SS.). } 7 \text { millones } \\
\text { de dólares en medios o publicidad ganada. } 4 \text { millones de menciones en RR.SS. Gran reper- } \\
\text { cusión en medios tradicionales: } 800 \text { noticias en el mundo. Posicionamiento de aportar valor } \\
\text { a la comunidad. }\end{array}$ \\
\hline
\end{tabular}

Fuente: elaboración propia.

\section{Abla Fahita. CBC (JWTMEA, 2015).}

\begin{tabular}{|l|l|}
\hline Mensaje & $\begin{array}{l}\text { Abla Fahita: marioneta cómica creada para un anuncio de Vodafone, que pasa a ser n० } 1 \text { de } \\
\text { audiencia en un canal de entretenimiento, e icono de Egipto. }\end{array}$ \\
\hline Soportes y acciones & Spot de TV, web, YouTube y RR.PP. \\
\hline Resultados & $\begin{array}{l}\text { Vídeo más visto en YouTube, en Egipto: } 1.394 .000 \text { visitas. № } 2 \text { de los canales de la cadena, } \\
\text { con su propio programa, tras } 5 \text { días. Se convirtió en icono de actualidad y reivindicación. } \\
\text { Llegó a ser investigada como terrorista por la fiscalía. }\end{array}$ \\
\hline
\end{tabular}

Fuente: elaboración propia.

\section{5. \#LikeAGirl [como una niña]. Procter \& Gamble (Always, 2015).}

\begin{tabular}{|c|c|}
\hline Mensaje & $\begin{array}{l}\text { El machismo del lenguaje afecta a las chicas desde la adolescencia (su público). Realizan un } \\
\text { experimento con chicas y chicos, a quienes dicen que demuestren qué es actuar"como una } \\
\text { niña". Las preadolescentes, libres de perjuicios, actúan con energía y poder. Pero los demás, } \\
\text { le dan una connotación negativa: ñoña, débil. Ellos se dan cuenta de lo absurdo y poderoso } \\
\text { del lenguaje. Se proponen frases positivas, que dan poder y dignidad a la mujer. }\end{array}$ \\
\hline Soportes y acciones & Experimento, web, RR.SS., spot de TV, campaña gráfica y campaña on-line. \\
\hline Resultados & $\begin{array}{l}\text { Vídeo más visto de P\&G: } 76 \text { millones de visitas. Compitió con los más vistos en YouTube y se } \\
\text { hizo viral. Empoderamiento femenino: engagement para la marca. Apropiación del posicio- } \\
\text { namiento de defensora de las mujeres, reivindicando su poder y capacidad. }\end{array}$ \\
\hline
\end{tabular}

Fuente: elaboración propia.

\section{Beer tooth implant [implante dental para cerveza]. CCU (AAP, 2015).}

Mensaje

Soportes y acciones

Resultados
Cerveza Salta. Lanzó un mensaje a los fanáticos del rugby. Aprovechando a los jugadores que perdieron dientes en un partido, creó un implante con su logotipo, abridor de botellas. Se lo colocaron a varios jugadores, que pueden abrir cervezas con la boca.

Spot de TV, campaña on-line, RR.SS., RR.PP., y YouTube.

En 48 h.: 700.000 visitas; 200.000 veces compartido en Facebook; 1.600 .0000 menciones en Twitter. Acción recogida por medios de todo el mundo. 


\section{Safety Truck [camión de la seguridad]. Samsung (2015).}

\begin{tabular}{|l|l|}
\hline Mensaje & $\begin{array}{l}\text { Volvo, Samsumg, una empresa de ingeniería y otra tecnológica desarrollaron un sistema } \\
\text { para disminuir accidentes al adelantar camiones (causa del } 80 \% \text { de accidentes alli). Cámaras } \\
\text { delanteras en el camión ven lo que hay, y una pantalla posterior, permite al conductor de } \\
\text { otros vehículos verlo, por si el adelantamiento es posible. }\end{array}$ \\
\hline Soportes y acciones & $\begin{array}{l}\text { Acción ad hoc (implantación en camiones de Argentina). Presentación patrocinada por unas } \\
\text { tiendas de electrodomésticos y tecnología. }\end{array}$ \\
\hline Resultados & $\begin{array}{l}\text { Hasta el momento de ser presentada, salvó vidas: } 1.400 .000 \text { km. de trayectos seguros, } 24.200 \\
\text { adelantamientos y ningún choque. Proyecto de aplicarlo, por ley, en camiones de más de } 7 \mathrm{~m} . \\
\text { Seleccionado como uno de los } 25 \text { mejores inventos de } 2015, \text { por la revista Time. Recoge la } \\
\text { atención mundial; Volvo y Samsung lo difunden internacionalmente. }\end{array}$ \\
\hline
\end{tabular}

Fuente: elaboración propia.

\section{Newcastle Band of Brands [la banda de marcas de Newcastle]. Heineken (MediaCat TV, 2015a).}

\begin{tabular}{|l|l|}
\hline $\begin{array}{l}\text { La cerveza Newcastle quería estar presente en la Super Bowl, diciendo que están dispuestos } \\
\text { a todo por aparecer, pero sin pagar tanto (presencia satírica en un concurso de Doritos, } \\
\text { del que fueron conscientemente descalificados, y otra campaña con storyboards), realizan } \\
\text { un spot con una famosa. Esta anima a otras marcas a aparecer juntos, para poder pagarlo. } \\
\text { Proponen un crowdfunding. Se hace la llamada en una televisión de California durante el } \\
\text { evento. Unos días antes, lanzan otro divertido spot, con las } 37 \text { marcas que respondieron. } \\
\text { Dicen que el fútbol es un deporte de equipo, y que el marketing también debe serlo. }\end{array}$ \\
\hline Soportes y acciones & \begin{tabular}{l} 
Spot de TV, web, crowdfunding, RR.SS. y RR.PP. \\
\hline Resultados
\end{tabular} \\
\hline $\begin{array}{l}\text { La campaña apareció en la Super Bowl en una TV local. Las personas que la vieron fueron } \\
\text { 356 respuestas de empresas en Twitter. Gran repercusión y simpatía de los consumidores } \\
\text { (2 billones en presencia en medios), 33 millones de visitas y 20 millones en medios ganados). } \\
\text { Involucró a } 37 \text { marcas, pese a que el llamamiento era de } 20 \text { a 30. Los medios lo recogieron } \\
\text { como uno de los mejores anuncios de la Super Bowl (Forbes, The Washington Post, Rolling } \\
\text { Stone, USA Today y muchos programas de TV). }\end{array}$ \\
\hline
\end{tabular}

Fuente: elaboración propia.

\section{Red Sox: Grenn Monster [monstruo verde]. Benjamin Moore (AdForum, 2015).}

\begin{tabular}{|l|l|}
\hline Mensaje & $\begin{array}{l}\text { La marca que pinta el estadio de béisbol de los Red Sox, Boston, propone la ayuda a la } \\
\text { renovación de los estadios juveniles, con una parte de la venta de una edición especial de } \\
\text { pinturas. El Green Monster es el más característico de sus colores. Proponen que los aficio- } \\
\text { nados pinten sus casas con ellos, y sacan a la calle un panel de resultados, para que inter- } \\
\text { relacionen con él. }\end{array}$ \\
\hline Soportes yacciones & Spot de TV, web, YouTube, patrocinio, vídeo y colección de pinturas. \\
\hline Resultados & $\begin{array}{l}\text { Se genera conversación y los medios lo recogen. Mayor identificación de los aficionados con } \\
\text { la marca. Patrocinio de la renovación de estadios juveniles. }\end{array}$ \\
\hline
\end{tabular}


10. Groceries not guns [supermercados no pistolas]. Moms demand action for gun sense in America (MediaCat TV, 2015b).

\begin{tabular}{|l|l|}
\hline \begin{tabular}{|l} 
Campaña para la concienciación de la prohibición de entrada con armas. Presionan a Kroger, \\
una de las mayores cadenas. Sacan a la luz su incoherencia (no dejan entrar con monopatín \\
o helados, pero sí con fusiles). Esto se visualiza gráficamente, preguntando a la gente quién \\
es bien recibido en Kroger. Primera parte de la campaña, y distintas acciones más, como \\
fomentar la compra en otras cadenas que no admitan armas, y subir a la página el ticket, \\
para cuantificar las pérdidas de Kroger.
\end{tabular} \\
\hline Campaña gráfica, spot de TV, web, YouTube y RR.SS. \\
\hline Soportes y acciones & $\begin{array}{l}360.000 \text { firmas y } 13.000 \text { llamadas. Apoyo del } 64 \% \text { de los consumidores (encuesta nacional). } \\
\text { Más de } 300,000 \$ \text { en tickets de compras de la competencia. Obama les apoyó. Kroger y otros } \\
\text { comercios prohibieron las armas. }\end{array}$ \\
\hline Resultados
\end{tabular}

Fuente: elaboración propia.

11. Social Savvy Burglar [ladrón social inteligente]. Allstate Insurance Company (Brand News, 2015).

El 78\% de los ladrones busca víctimas en las RR.SS., pues se da mucha información en ellas. La compañía entra en la casa de una pareja, que publica una foto en un partido de fútbol. Un

Mensaje ladrón aprovecha, destroza la casa, poniendo en venta todo, hasta el coche, a través de una web (en realidad, página de la aseguradora). El anuncio, con el ladrón en directo, se proyecta en una pantalla del estadio, y es visto por las víctimas. Conscientes, frente a inconscientes (quienes no sé dan cuenta que publicando todo en las redes, se exponen).

Soportes y acciones

RR.SS., web, RR.PP., y vídeo.

Resultados

Trending topic mundial. Generó conversación, recogida por los medios. Se abre el debate sobre si hacemos bien publicando todo en las RR.SS. 95 millones de apariciones en medios. 33 millones de visitas a la página. 18\% de incremento en pólizas de hogar.

Fuente: elaboración propia.

12. Monty`s Christmas [las Navidades de Monty]. Jhon Lewis Partnership (Brand Buffet, 2015b).

\begin{tabular}{|c|c|}
\hline Mensaje & $\begin{array}{l}\text { Grandes almacenes que realizan esperadas campañas. En esta ocasión, emocionan. Un spot, } \\
\text { con dos mejores amigos (un chico y su pingüino). Aquel quiere encontrar el amor, para lo } \\
\text { que el niño le consigue otro pingüino. Al final, los animales se convierten en Monty y Mabel } \\
\text { (peluches). Emotiva canción de los Beatles. Se hizo libro, visor de cartón, juguete electrónico } \\
\text { y otros productos que se vendieron en tiendas y on-line, y que estaban en sus escaparates. }\end{array}$ \\
\hline Soportes y acciones & Spot de TV, YouTube, RR.SS., muchos productos, merchandising y RR.PP. \\
\hline Resultados & $\begin{array}{l}4,6 \text { millones de visitas en YouTube. Antes de ser proyectado en TV, } 100.000 \text { personas } \\
\text { siguieron la campaña. } 2 \text { minutos en TV, Canal } 4 \text {. Generó conversación. La prensa lo recogió. } \\
\text { Más de } 100.000 \text { personas los siguieron. } 32 \text { millones de visitas en YouTube y en Facebook } \\
\text { (6.9 millones en } 24 \text { horas), antes de ser emitido en TV. Se compartió en Facebook } 165.000 \text { veces. } \\
\text { Trending topic mundial, durante una hora. Los juguetes se agotaron en tres horas. En WWF } \\
\text { las adopciones de pingüinos aumentaron un } 600 \% \text { (recogido por los medios). El single, nº } 3 \\
\text { en lista de éxitos, el primer fin de semana. Cientos de parodias. Tema de moda. John Lewis } \\
\text { batió records de venta. }\end{array}$ \\
\hline
\end{tabular}




\section{Horse With Harden [caballito con Harden]. Foot Locker (2015).}

\begin{tabular}{|l|l|}
\hline Mensaje & $\begin{array}{l}\text { Foot Locker, tienda de ropa y calzado deportivo. Dejó a los fans la posibilidad de jugar a } \\
\text { Horse (juego de baloncesto) con la superestrella James Harden. Tenían que tuitear vídeos } \\
\text { propios, realizando sus mejores lanzamientos, y él debía igualarlos. Sus intentos fueron } \\
\text { tuiteados en directo, con la puntuación. Harden vs Internet. }\end{array}$ \\
\hline Soportes y acciones & Web, RR.SS., YouTube y juego con jugadores y aficionados. \\
\hline Resultados & $\begin{array}{l}\text { Llegó a } 61 \text { millones de personas y multiplicó por } 10 \text { el tráfico habitual hacia la web. 350\% } \\
\text { más de suscripciones. }\end{array}$ \\
\hline
\end{tabular}

Fuente: elaboración propia.

14. Love has no labels [el amor no tiene etiquetas]. Adcouncil (2015).

\begin{tabular}{|l|l|}
\hline $\begin{array}{l}\text { EE.UU. Campaña contra la discriminación, del mayor promotor de anuncios de servi- } \\
\text { cio público. Promovida por } 6 \text { marcas y } 8 \text { asociaciones sociales. Aunque creemos no tener } \\
\text { prejuicios, los creamos, basados en lo que vemos: raza, edad, género, religión, sexo. Prejuicios } \\
\text { inconscientes. El experimento demuestra que todos somos iguales. Colocaron una pantalla } \\
\text { de rayos } X \text { en Santa Mónica, en San Valentín, y filmaron a personas de diferentes géneros, } \\
\text { religiones... bailando detrás y después saliendo al frente, ante una audiencia curiosa y sor- } \\
\text { prendida, de ver lo que no pensaban que habían visto: lesbianas, niñas discapacitadas, fa- } \\
\text { milias de gays, parejas de distinta raza o religión, etc. }\end{array}$ \\
\hline Soportes y acciones & Web, RR.SS., web, YouTube y vídeo. \\
\hline Resultados & Viral, 15,5 millones de visitas y ritmo de crecimiento poco visto. \\
\hline
\end{tabular}

Fuente: elaboración propia.

15. Risk Everything [arriesga todo]. Nike (Fmcomms, 2015b).

\begin{tabular}{|l|l|}
\hline $\begin{array}{l}\text { Mundial de fútbol. Buscan vincularse a él, y desbancar al patrocinador, Adidas. Varias realizacio- } \\
\text { nes y entregas, con distintos famosos. Película animada "El que gana el partido, se queda", } \\
\text { "El fútbol siempre pertenecerá a aquellos que lo arriesgan todo". Esta parte es The last game [la } \\
\text { última jugada]. Al final, un joven anónimo dispara a portería, y puede ser cualquier especta- } \\
\text { dor, "dándolo todo". }\end{array}$ \\
\hline Soportes y acciones & Spot de TV y RR.SS. \\
\hline Resultados & 122,2 millones de visitas. La campaña más vista de Nike, y de la historia de los mundiales. \\
\hline
\end{tabular}

Fuente: elaboración propia.

16. Emily's $\mathrm{Oz}$ [el mago de $\mathrm{Oz}$ de Emily]. Xfinity (2015).

\begin{tabular}{|l|l|}
\hline Mensaje & $\begin{array}{l}\text { Lanzada durante los Óscars, para mostrar un sistema de accesibilidad de una compañía de } \\
\text { Tv por cable, que facilita a discapacitados visuales, la selección y visión de la oferta televi- } \\
\text { siva, con el mando. Se preguntó a Emily, niña ciega, qué veía cuando oía El Mago de Oz. La } \\
\text { agencia logró recrearlo con escenógrafos, diseñadores, maquilladores... y ella lo ella tocó y } \\
\text { vivió. Se hizo un vídeo espectacular. Emily fue una revelación para el mundo. La voz del off, } \\
\text { de Robert Redford. }\end{array}$ \\
\hline Soportes y acciones & Spot de TV, YouTube y recreación física de escenarios y personajes. \\
\hline Resultados & La niña se hizo famosa. Campaña muy notoria y entrañable. No hay datos más concretos. \\
\hline
\end{tabular}

Fuente: elaboración propia. 


\section{I will what I want [seré lo que yo quiera]. Under Armour (Under Armour, 2014).}

Deja atrás a estrellas del fútbol, para contar con mujeres deportistas, y mensaje de empoderamiento femenino. Las alienta para que saquen su fuerza interior y hagan lo que quieran, no lo que le digan los demás. Uno de los anuncios, con la bailarina Misty Copeland. Mientras realiza impresionantes saltos de ballet, se oye un off que recita una carta de rechazo. "Tienes un cuerpo equivocado para el ballet. Y a los 13, eres demasiado vieja". Re-

Mensaje sumen de lo que le dijeron cuando empezó a aprender. Pero no hizo caso, y consiguió ser la primera mujer afroamericana en bailar sola en el American Ballet Theatre. En otro vídeo, Gisele Bündchen, supermodelo, golpea un saco de arena, en tiempo real, mientras se ven los comentarios en las RR.SS. Ella utiliza su fuerza, para bloquear las críticas. La campaña demuestra que las redes pueden hablar de uno, o influir en la percepción que la mujer tenga de sí. Pero ésta puede tomar el control y hacer "lo que ella quiera".

Soportes y acciones

Spot de TV, publicidad exterior, RR.SS. y experiencia digital en tiempo real, con la modelo golpeando el saco, a la vez que la gente le escribía.

Resultados

Los medios se hacen eco. Entrevistan a la protagonista. Aparece como noticia en los principales periódicos y televisiones. Medio millón de visitas. Gisele dio lugar a 1,5 mil millones de apariciones en medios. 15 millones en medios ganados. Cuatro minutos de permanencia en el sitio, en el pico de la campaña. $42 \%$ más de visitas a la página, y $28 \%$ más en ventas.

Fuente: elaboración propia.

18. Look at me [mírame]. Samsung (Fmcomms, 2015a).

Mensaje

Soportes y acciones

Resultados
Desarrollo de la aplicación para todo el mundo, que ayuda a niños autistas a mejorar sus habilidades de comunicación y leer expresiones faciales. Fácil, divertida y gratuita. Médicos, profesores y desarrolladores trabajaron juntos.

App y ensayo clínico de 8 semanas, con 20 niños.

Ayudó a los niños a comunicarse mejor. El $60 \%$ obtuvo mejor contacto visual, y el $40 \%$, mejoría en la expresión emocional. Se lanzó en Corea del Sur y Canadá, y luego, internacionalmente. Una semana después, una de las aplicaciones más descargadas en educación ( $3^{a}$ en Reino Unido, $4^{a}$ en EE.UU. y $5^{a}$ en Brasil). Las descargas y la cobertura de los medios aumentaron espectacularmente.

Fuente: elaboración propia.

19. Hearing Hands [manos que escuchan]. Samsung (Digital Synopsis, 2015).

Mensaje

Soportes y acciones

Resultados
Plataforma de vídeollamadas Duyan Eller, para personas con discapacidad auditiva. Para comunicar que nuestro mundo sería mejor si no hubiese barreras, hizo que muchos obstáculos que tiene que superar una persona sorda, se derrumbasen a través del aprendizaje del lenguaje de signos de quien interactúo con el protagonista. Su reacción fue muy emotiva, porque pudo entender y comunicarse con todas las personas de su alrededor. (Presupuesto: 30.000 euros.)

Vídeo, RR.SS., YouTube y RR.PP.

Más de 32 millones de visionados en YouTube. 17 millones de personas en Facebook. 232 millones de menciones en Twitter. 3,2 millones en medios ganados. Traducción al lenguaje de signos de las sesiones del Parlamento. 
20. The Monster-Smart Launch [lanzamiento del Smart-monstruo]. Daimler AG / Smart MM (BBDO Group Germany, 2015).

\begin{tabular}{|l|l|}
\hline Mensaje & $\begin{array}{l}\text { Para crear expectación ante el lanzamiento del nuevo modelo de Smart, se lanzó una cam- } \\
\text { paña teaser, con un modelo exageradamente grande. Éste se testó en focus groups y su resul- } \\
\text { tado se comunicó a través de YouTube y redes sociales. Aunque finalmente se supo que era } \\
\text { una broma, la campaña consiguió generar mucho ruido antes del lanzamiento real. }\end{array}$ \\
\hline Soportes y acciones & Vídeos, RR.SS., RR.PP. y YouTube. \\
\hline Resultados & $\begin{array}{l}\text { Numerosos comentarios en RR.SS. Cobertura en prensa. Más visitas a la web de Smart. Visio- } \\
\text { nados en YouTube. Una semana antes del lanzamiento: viral n’1 en Alemania. Gran expec- } \\
\text { tación el día de la presentación del nuevo modelo. }\end{array}$ \\
\hline
\end{tabular}

Fuente: elaboración propia.

21. The Other Side [la otra cara]. Honda (MediaCat TV, 2015c).

\begin{tabular}{|l|l|}
\hline Mensaje & $\begin{array}{l}\text { Honda quiso mostrar la doble faceta de uno de sus automóviles. Para ello, produjo un vídeo } \\
\text { donde el espectador podía cambiar de historia pulsando una tecla. Una historia reflejaba } \\
\text { el aspecto familiar del coche y su conducción eficiente; y la otra, el deportivo y aventurero, } \\
\text { con mucha potencia. }\end{array}$ \\
\hline Soportes y acciones & Vídeo, RR.PP. y web. \\
\hline Resultados & Cobertura en prensa. \\
\hline
\end{tabular}

Fuente: elaboración propia.

22. Made by You [hecho por ti]. Converse (Commercials HD, 2015).

\begin{tabular}{|l|l|}
\hline $\begin{array}{l}\text { Celebración del centenario de las zapatillas Chuck Taylor All Star, uno de sus modelos estrella, } \\
\text { con una campaña basada en el insight "todos queremos tener nuestro auténtico y verdadero yo } \\
\text { en este mundo". Campaña donde diferentes personas, con diferentes profesiones y trayec- } \\
\text { torias, conocidas y anónimas, se definían, diciendo que sus Chuck Taylor All Star, reflejaban } \\
\text { su personalidad. Fotografías de las zapatillas de quienes participaron en la campaña para } \\
\text { ilustrar la vida de sus dueños. }\end{array}$ \\
\hline $\begin{array}{l}\text { Publicidad exterior, punto de venta, estudios fotográficos pop-up, eventos, RR.SS. y exposi- } \\
\text { ciones en Nueva York, Londres, Beijing, y México DF. }\end{array}$ \\
\hline Resultados & No mencionados. \\
\hline
\end{tabular}

Fuente: elaboración propia.

23. The Berlin Wall of Sound [el Muro de Berlín de sonidos]. Soundcloud (Grey Berlin, 2015).

\begin{tabular}{|c|c|}
\hline Mensaje & $\begin{array}{l}\text { Para conmemorar el } 25^{\circ} \text { aniversario de la caída del Muro, la plataforma on-line de música, } \\
\text { Soundcloud, hizo una reconstrucción acústica, para reproducir las emociones de aquella } \\
\text { época (tiros, megafonía, sirenas...). Se insertaron imágenes de personas que murieron } \\
\text { atravesándolo. La canción duraba 7:32 min. (tiempo que se tardaba en recorrer el muro). }\end{array}$ \\
\hline Soportes y acciones & Creación de melodía y web. \\
\hline Resultados & No mencionados. \\
\hline
\end{tabular}

Fuente: elaboración propia. 
24. Radiant Return [el regreso de Radiant]. PZ Cussons (Ampliffy Videos, 2014).

\begin{tabular}{|l|l|}
\hline Mensaje & $\begin{array}{l}\text { Australia. El detergente Radiant estaba a punto de descatalogarse. Para probar su eficacia y } \\
\text { que “con Radiant la ropa parecen más nueva", se compraron } 14 \text { prendas, y se ensuciaron al } \\
\text { máximo. Una vez lavadas y planchadas, intentaron devolverlas. Y se consiguió en } 13 \text { de } 14 \\
\text { prendas, que pasaron por nuevas. La campaña se basó, en las reacciones de los dependien- } \\
\text { tes cuando se enteraron que era un test para demostrar la eficacia; y en las terribles pruebas } \\
\text { a las que sometieron a las prendas. }\end{array}$ \\
\hline Soportes y acciones & Prueba de producto, vídeos, spot de TV, radio, web, RR.SS., YouTube y RR.PP. \\
\hline Resultados & $\begin{array}{l}\text { Interacciones en RR.SS. Se convirtió en el detergente n० } 1 \text { en supermercados. Aumento de } \\
\text { ventas: } 27 \% \text {. Mayor cuota de mercado en } 5 \text { años. }\end{array}$ \\
\hline
\end{tabular}

Fuente: elaboración propia.

25. Between Us [entre nosotras]. Vodafone (Brand Buffet, 2015c).

\begin{tabular}{|l|l|}
\hline Mensaje & $\begin{array}{l}\text { Turquía. } 1 \text { de cada } 3 \text { mujeres es víctima de violencia doméstica. Está mal visto que pida } \\
\text { ayuda. Para comunicar que la tecnología puede ser una buena herramienta para hacer el } \\
\text { bien, Vodafone creó una App para pedir ayuda secretamente. Se avisaba a tres personas del } \\
\text { círculo de la mujer, en caso de agitar el terminal; si el teléfono lo cogía el hombre, la App } \\
\text { reconocía la voz masculina y proporcionaba un mensaje comercial. Una vez que la App fue } \\
\text { conocida, comenzó la segunda fase con una actualización. La App se convertía en un espejo } \\
\text { y se dio a conocer a través de mensajes secretos en banners. }\end{array}$ \\
\hline Soportes y acciones & Etiquetas de ropa, bandas de depilación, carteles en peluquerías, campaña on-line, vídeos y RR.PP. \\
\hline Resultados & 254.000 descargas (24\% de las mujeres con Smartphone). Se activó más de 100.000 veces. \\
\hline
\end{tabular}

Fuente: elaboración propia.

26. Nazis against Nazis [Nazis contra Nazis]. ZDK Gesellschaft Demokratische Kultur (Rechts gegen Rechts, 2014).

\begin{tabular}{|l|l|}
\hline Mensaje & $\begin{array}{l}\text { El movimiento nazi crece en Alemania, donde distintos grupos hacen manifestaciones, para } \\
\text { atemorizar. Para acabar con ello, se creó una manifestación paralela, donde, por cada metro } \\
\text { recorrido por ellos, se donaban } 10 \text { euros a favor de la ONG Exit-Deutschland, que ayuda a } \\
\text { quienes quieren salir de estos grupos. }\end{array}$ \\
\hline Soportes y acciones & Vídeo, YouTube, RR.PP., lonas y RR.SS. \\
\hline Resultados & $\begin{array}{l}\text { Donaciones: } 10.000 \text { euros. Cobertura en prensa en } 42 \text { países. Menciones en RR.SS. } 279 \text { millones } \\
\text { de impresiones. Cobertura en medios: 1,3 millones Incremento de donaciones } 1000 \% .\end{array}$ \\
\hline
\end{tabular}

Fuente: elaboración propia.

27. House of Mamba [la casa de Mamba]. Nike (MarketeerChannel, 2015).

\begin{tabular}{|l|l|}
\hline \multirow{2}{*}{ Mensaje } & $\begin{array}{l}\text { En China, país muy aficionado al baloncesto, Nike creó la primera cancha de baloncesto LED } \\
\text { interactiva. Se seleccionó a los mejores jugadores amateurs, que jugarían en el Campeonato } \\
\text { nacional Rise. El juego cambiaba con distintos entrenamientos, y análisis de movimientos } \\
\text { y resultados, mostrándose gráficamente. Los ganadores pasarían a la final, y tendrían una } \\
\text { semana de entrenamiento con Kobe Bryant. }\end{array}$ \\
\hline Soportes y acciones & $\begin{array}{l}\text { Experiencia para jugadores, con cancha de baloncesto LED interactiva, con sensores de movi- } \\
\text { miento, vídeo y aplicaciones. }\end{array}$ \\
\hline Resultados & $\begin{array}{l}\text { Notoriedad por el soporte. Conexión con el consumidor, gracias a la tecnología y el valor que } \\
\text { les ofrecía. Atención de los aficionados chinos y curiosidad del resto del mundo. Aumento de } \\
\text { la vinculación emocional con la marca. Ofrecía una experiencia a jugadores, y a espectadores. }\end{array}$
\end{tabular}

Fuente: elaboración propia. 


\section{Holograms for Freedom [hologramas por la libertad]. No Somos Delito (2015).}

\begin{tabular}{|c|c|}
\hline Mensaje & $\begin{array}{l}\text { España. La aprobación de la "Ley Mordaza" causó malestar en la sociedad: prohibición de } \\
\text { manifestarse ante el Congreso, merma de libertades... Para demostrarlo, se creó la primera } \\
\text { manifestación de hologramas, donde personas que subían su imagen a través de una web, } \\
\text { tomaron forma de holograma para participar en una manifestación digital, con el lema:"Ley } \\
\text { Mordaza, es una amenaza". }\end{array}$ \\
\hline Soportes y acciones & Página web, hologramas, RR.SS. y RR.PP. \\
\hline Resultados & $\begin{array}{l}\text { Repercusión en medios nacionales e internacionales. Llegó a } 800 \text { millones de personas en } \\
\text { todo el mundo. } 400 \text { millones de menciones en RR.SS. } 300 \text { mil personas firmaron la petición } \\
\text { para retirar la Ley. La protesta se mencionó en el Congreso. }\end{array}$ \\
\hline
\end{tabular}

Fuente: elaboración propia.

\section{The Marathon Walker [la maratoniana]. Water for Africa (Ogilvy \& Mather, 2015).}

Mensaje

Soportes y acciones

Resultados
Contra la escasez de pozos de agua en África. Las mujeres tienen que caminar diariamente $40 \mathrm{Km}$., para conseguir agua. Para darlo a conocer y recaudar fondos, una mujer africana recorrió el maratón de París con 20 I. en su cabeza y este cartel: "Las mujeres recorren la misma distancia para conseguir agua limpia"y“Ayúdanos a reducir la distancia". En la web se podían donar pasos para acortar esas distancias.

Cartel que la mujer africana portaba durante el maratón y RR.PP.

Trending topic en Twitter. Numerosa cobertura en medios franceses e internacionales. Las donaciones han permitido construir cinco pozos.

Fuente: elaboración propia.

30. Proud Whopper [el orgullo Whopper]. Burger King (David, 2015).

Mensaje

Soportes y acciones

Resultados
Para comunicar que todos somos iguales, independientemente de la orientación sexual, se creó el "Orgullo Whopper". Se vendió en San Francisco en el Orgullo Gay 2014. Se podía leer en el envoltorio: "todos somos iguales en el interior".

Packaging, vídeo, RR.SS., venta del envoltorio, YouTube y RR.PP.

1.1 mil millones de impresiones. 21 millones de dólares en medios ganados. 7 millones de visionados. 450.000 menciones en blogs. Trending topic en Facebook y Twitter en una semana. La hamburguesa se convirtió en símbolo de igualdad.

Fuente: elaboración propia.

\section{The Face of Litter [la cara de la basura]. Hong Kong Cleanup (Advert, 2015).}

Mensaje

Soportes y acciones

Resultados
Objetivo: reducir la basura que se tira en la calle. Para ello, se quiso poner cara quien lo hace, para hacerles sentir vergüenza. Se diseñaron retratos robot gracias al ADN de los desperdicios recogidos, y se colocaron en las calles.

Vídeo, publicidad exterior, RR.SS. y RR.PP.

En dos semanas: 3,9 millones de interacciones en RR.SS., y 5 millones de dólares en medios propios.

Fuente: elaboración propia. 
32. 805 Million Names [805 millones de nombres]. World Food Programme (2015).

\begin{tabular}{|l|l|}
\hline Mensaje & $\begin{array}{l}\text { Para dar voz a millones de personas que pasan hambre, el futbolista lbrahimovic se tatuó } \\
15 \text { nombres, como muestra, y lo enseñó al meter un gol en el partido Paris Saint Germain } \\
\text { vs. Caen }(14 / 2 / 2015) \text {. Él sabía que le amonestarían al quitarse la camiseta y, que lograría la } \\
\text { atención de espectadores y medios. }\end{array}$ \\
\hline Soportes y acciones & Tatuaje en el cuerpo, RR.SS., campaña on-line, vídeo y RR.PP. \\
\hline Resultados & $\begin{array}{l}\text { Más de } 4.500 \text { reportajes y artículos. } 4.4 \text { millones de interacciones en RR. SS. La campaña llegó } \\
\text { a } 877 \text { millones de personas. }\end{array}$ \\
\hline
\end{tabular}

Fuente: elaboración propia.

33. Reduce Speed Dial [reducir la velocidad del coche]. Volkswagen (2015).

\section{Mensaje}

Soportes y acciones

Resultados
Objetivo: reducir la velocidad en carretera, porque lo dice alguien querido. Para comunicarlo, eligieron a familias, e instalaron cuentaquilómetros con mensajes dibujados por los niños de aquellas.

Vídeo y diseño de cuentaquilómetros infantiles.

Las familias que participaron, redujeron la velocidad del coche en muchas ocasiones.

Fuente: elaboración propia.

34. Elan Taste the Translation [Elan saborea la traducción]. Elan (J. Walter Thomson, 2015).

\begin{tabular}{|l|l|}
\hline Mensaje & $\begin{array}{l}\text { La campaña quiere comunicar la mayor precisión de las traducciones de la herramienta on- } \\
\text { line de Elan, en comparación con la de Google. Para ello, tradujo una misma receta japonesa } \\
\text { con ambas, y un cocinero se encargó de elaborarlas. Después, varias personas, hicieron una } \\
\text { cata a ciegas de las dos. }\end{array}$ \\
\hline Soportes y acciones & Elaboración de una receta, cata a ciegas y vídeo. \\
\hline Resultados & A los participantes les gustó más el plato que seguía las instrucciones traducidas con Elan. \\
\hline
\end{tabular}

Fuente: elaboración propia.

35. First Days Out [primeros días fuera]. Mars Brasil (Pedigree, 2015).

\begin{tabular}{|l|l|}
\hline Mensaje & $\begin{array}{l}\text { Se eligieron dos presos recién salidos de la cárcel, para que adoptaran un perro. La disciplina } \\
\text { de su cuidado, beneficiaba a los presos, y a los perros, por tener un cuidador. }\end{array}$ \\
\hline Soportes y acciones & Documental, RR.SS., RR.PP.y YouTube. \\
\hline Resultados & $\begin{array}{l}\text { Un } 80 \% \text { más suscripciones al canal de YouTube. Un } 99 \% \text { de aprobaciones. En una semana: } \\
142.000 \text { likes en Facebook y contenido compartido } 78.000 \text { veces. }\end{array}$
\end{tabular}

Fuente: elaboración propia.

36. Security Moms [las madres que velan por la seguridad]. Sport Clube do Recife (Ogilvy, 2015).

Mensaje
Soportes y acciones
Resultados

Fuente: elaboración propia.
La violencia en el fútbol es habitual en Brasil. Para evitar muertes y heridos, se creó un grupo de seguridad formado por las madres de los más radicales. Fue un éxito, porque nadie quiere pelearse ante su madre.

Acción in situ, vídeo y RR.PP.

No hubo ningún incidente durante el partido. Los medios lo recogieron. 
37. The Gun Shop [la tienda de armas]. States United To Prevent Gun Violence (2015).

\begin{tabular}{l|l}
\hline Mensaje & $\begin{array}{l}\text { El } 60 \% \text { de norteamericanos se sienten más seguros con armas. La campaña cuenta que } \\
\text { "todas las pistolas tienen una historia detrás" (la de las muertes que produjeron). }\end{array}$ \\
\hline Soportes y acciones & Tienda física y on-line, RR.PP., vídeos, YouTubey RR.SS. \\
\hline Resultados & $\begin{array}{l}\text { El } 80 \% \text { de clientes cambió de opinión. El 94\% de visitantes de la web completó la encuesta. La } \\
\text { petición de firmas subió un 1250\%. }\end{array}$
\end{tabular}

Fuente: elaboración propia.

\section{Resultados de la investigación}

Dado que el presente estudio compara las campañas integradas del Festival El Sol 2014 y el de
Cannes Lions 2015, vemos necesario facilitar la siguiente tabla que resume las campañas estudiadas del Festival El Sol 2014.

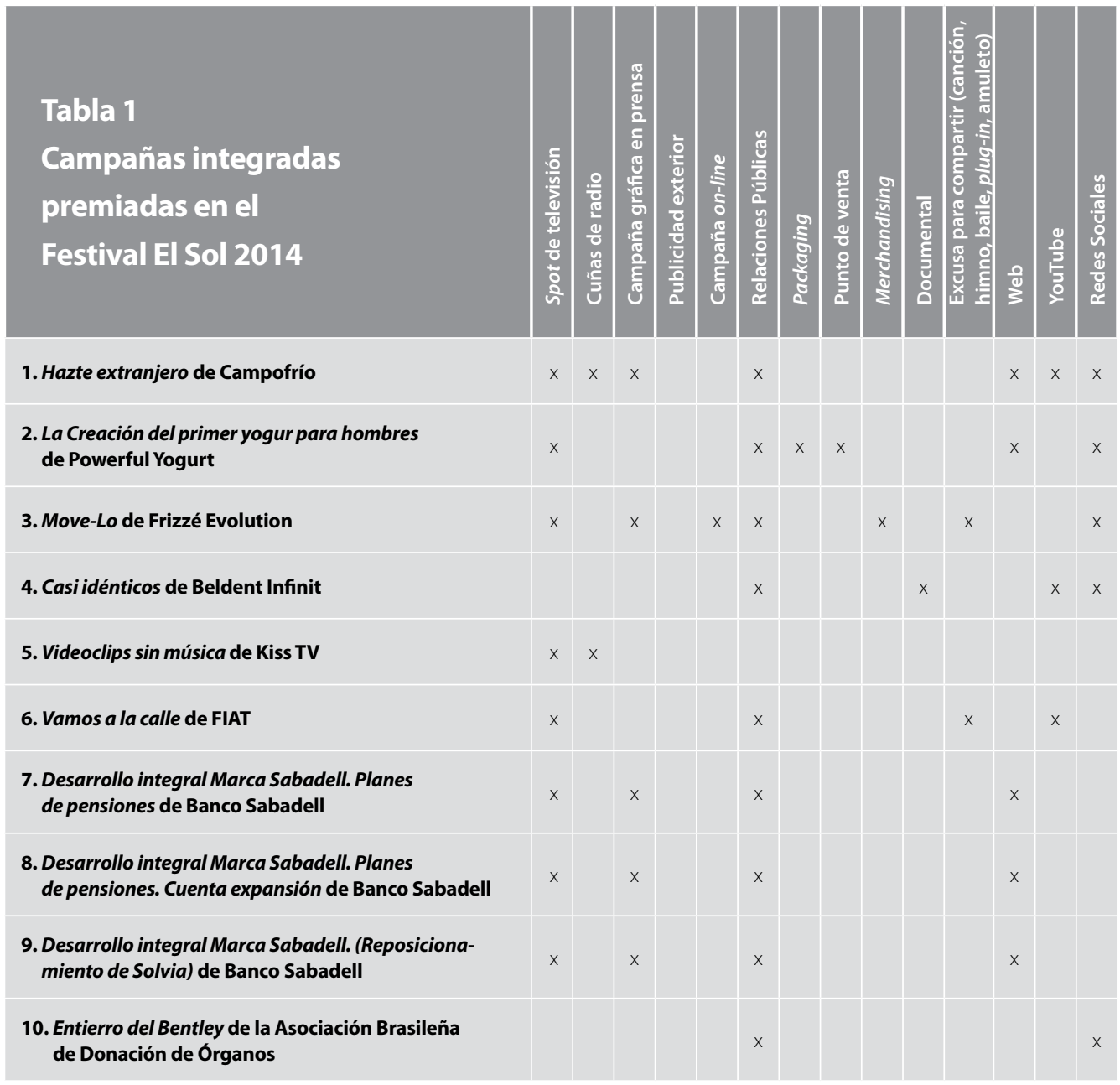




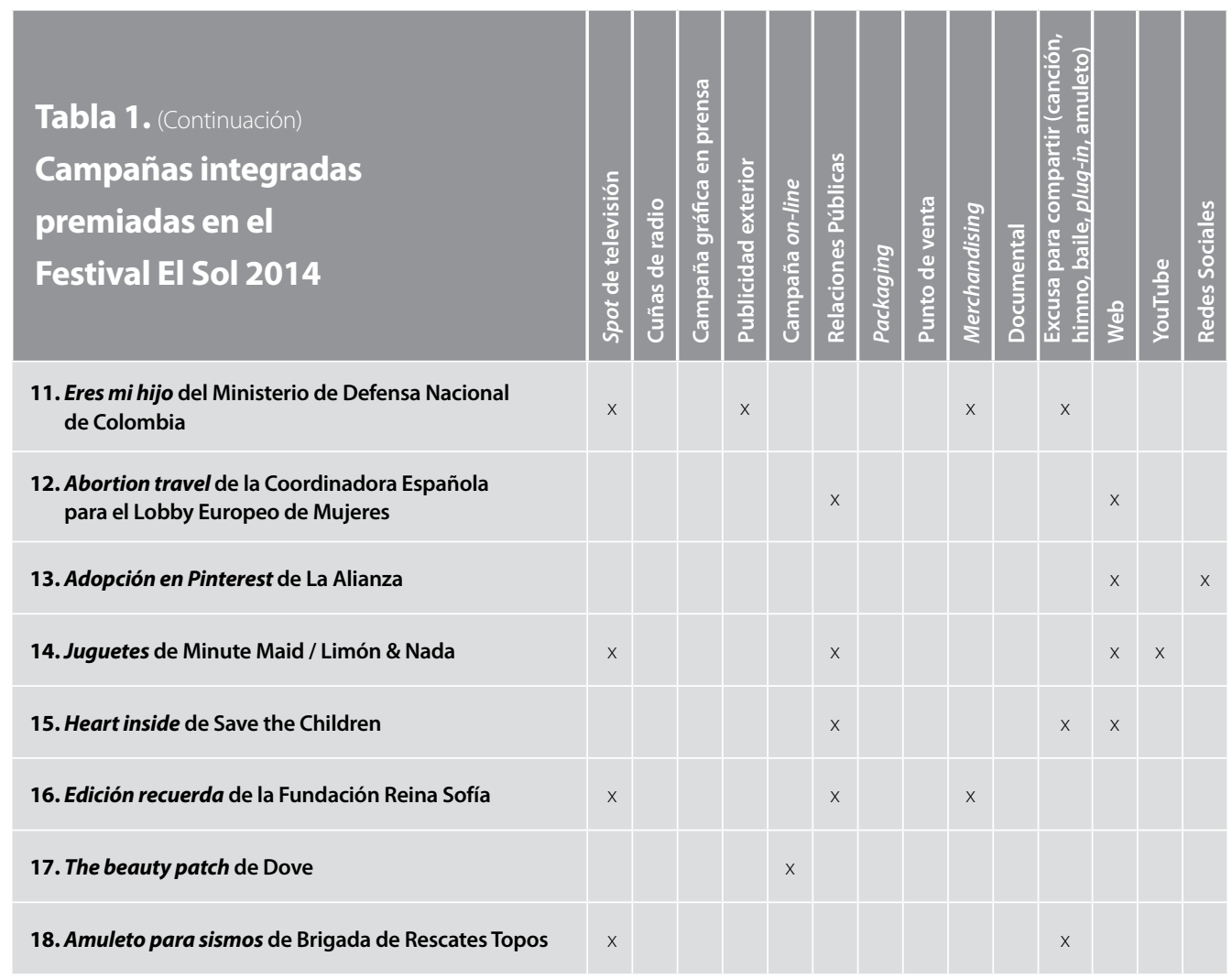

Fuente: Carretero, Rangel, 2017.

En los siguientes apartados, se expondrán los resultados cuantitativos y después los cualitativos de las campañas de Cannes Lions 2015, para poder compararlos con los resumidos anteriormente del Festival El Sol 2014.

\subsection{Resultados del análisis cuantitativo}

A continuación se detalla el análisis cuantitativo de la investigación, donde se hace una relación de acciones por campaña, se destacan las más utilizadas y se realiza una distinción entre medios convencionales y no convencionales. Todo ello sin entrar a valorar la creatividad u originalidad de las campañas.(Veáse tabla no 2 ).

En el gráfico destacan dos campañas por utilizar más herramientas diferentes, en concreto, ocho: la 5. En segundo lugar, destacan tres campañas donde se han utilizado siete elementos distintos: la 6, 9 y 12. En tercer lugar, la campaña 16, con seis elementos diferentes utilizados (Veáse gráfico 1, pág. 25).

Tal y como se desprende de la lectura del gráfico, las acciones más utilizadas fueron, en primer lugar, la creación de contenido audiovisual ad hoc; después, el uso de RR.SS. y RR.PP; y en tercer lugar, acciones en el punto de venta o en el lugar donde se desarrollaba el acto, evento o experimento. Por el contrario, las herramientas menos utilizadas fueron merchandising, patrocinios, cuñas de radio y publicidad exterior. (Veáse gráfico 2, pág. 25 ). 


\begin{tabular}{|c|c|c|c|c|c|c|c|c|c|c|c|c|c|c|c|}
\hline \multirow[b]{2}{*}{$\begin{array}{l}\text { Tabla } 2 \\
\text { Relación de acciones por } \\
\text { campaña del Festival } \\
\text { Cannes Lions } 2015 \\
\text { Titanium and Integrated }\end{array}$} & \multicolumn{5}{|c|}{ Medios convecionales } & \multicolumn{10}{|c|}{ Medios no convecionales } \\
\hline & 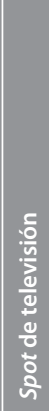 & 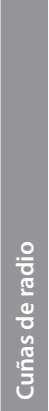 & 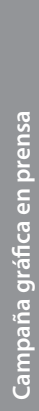 & $\begin{array}{l}\frac{.}{3} \\
\frac{0}{y} \\
\frac{0}{0} \\
\frac{0}{0} \\
\frac{\pi}{0} \\
\frac{0}{0} \\
\frac{0}{2} \\
\end{array}$ & 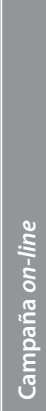 & 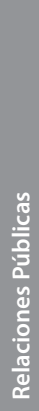 & 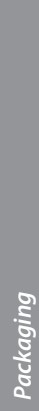 & 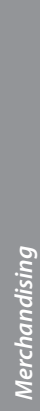 & 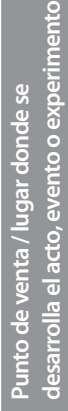 & 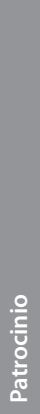 & 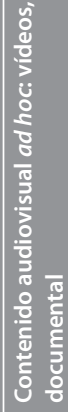 & 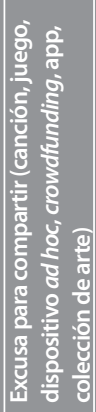 & $\frac{20}{3}$ & $\begin{array}{l}\frac{2}{3} \\
\frac{2}{3} \\
\text { ¿ }\end{array}$ & 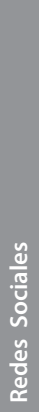 \\
\hline 1. Pedidos Emoji de Domino's Pizza & & & & & & $x$ & & & & & $x$ & & $x$ & $x$ & \\
\hline 2. \#re2pect de Michel Jordan & $x$ & & & $x$ & & $x$ & & & $x$ & & & & & & $x$ \\
\hline 3. Clever Buoy de Optus & & & & & & $x$ & & & & & $x$ & $x$ & $x$ & $x$ & \\
\hline 4. ABLA Fahita de CBC & $x$ & & & & & $x$ & & & & & & & & & \\
\hline 5. \#COMO UNA NIÑA de Procter \& Gamble & $x$ & & $x$ & & $x$ & $x$ & & & & & $x$ & & $x$ & $x$ & $x$ \\
\hline 6. BEER implante dental de CCU & $x$ & & & & $x$ & $x$ & & & & & $x$ & & $x$ & $x$ & $x$ \\
\hline 7. Safety Truck de Samsung & & & & & & $x$ & & & & & & $x$ & & & \\
\hline 8. Newcastle Band of Brands de Heineken & $x$ & & & & & $x$ & & & & & & & & & $x$ \\
\hline 9. Red Sox: Grenn Monster de Benjamin Moore & $x$ & & & & & & & & $x$ & $x$ & $x$ & $x$ & $x$ & $x$ & \\
\hline $\begin{array}{l}\text { 10. Groceries not guns de Moms demand } \\
\text { action for gun sense in America }\end{array}$ & $x$ & & & $x$ & & & & & & & $x$ & & $x$ & $x$ & $x$ \\
\hline 11. Social Savvy Burglar de Allstate Insurance & $x$ & & & & & $x$ & & & $x$ & & $x$ & & & & $x$ \\
\hline $\begin{array}{l}\text { 12. Monty`s Christmas de Jhon Lewis } \\
\text { Partnership }\end{array}$ & $x$ & & & & & $x$ & & $x$ & & & $x$ & $x$ & & $x$ & $x$ \\
\hline 13. Horse With Harden de Foot Locker & & & & & & & & & & & $x$ & $x$ & & $x$ & $x$ \\
\hline 14. Love has no labels de Adcouncil & & & & & & & & & & & $x$ & & $x$ & $x$ & $x$ \\
\hline 15. Risk Everything de Nike & $x$ & & & & & & & & $x$ & & & & $x$ & & $x$ \\
\hline 16. Emily's Oz de Comcast / Xfinity & $x$ & & & & & & & & $x$ & & & & & & $x$ \\
\hline 17. I will what i want de Under Armour & $x$ & & & $x$ & & $x$ & & & & & & & & & $x$ \\
\hline 18. Look at me de Samsung & & & & & & $x$ & & & $x$ & & & $x$ & & & \\
\hline 19. Hearing Hands de Samsung & & & & & & $x$ & & & & & $x$ & & & $x$ & $x$ \\
\hline $\begin{array}{l}\text { 20. The Monster-Smart Launch de Daimler } \\
\text { AG / Smart MM }\end{array}$ & & & & & & & & & & & $x$ & & & & \\
\hline
\end{tabular}




\begin{tabular}{|c|c|c|c|c|c|c|c|c|c|c|c|c|c|c|c|}
\hline \multirow[b]{2}{*}{$\begin{array}{l}\text { Tabla 2. (Continuación) } \\
\text { Relación de acciones por } \\
\text { campaña del Festival } \\
\text { Cannes Lions } 2015 \text {, } \\
\text { Titanium and Integrated }\end{array}$} & \multicolumn{5}{|c|}{ Medios convecionales } & \multicolumn{10}{|c|}{ Medios no convecionales } \\
\hline & 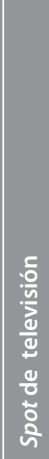 & 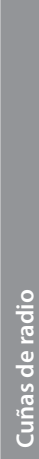 & 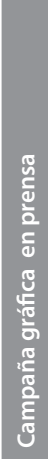 & 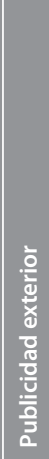 & 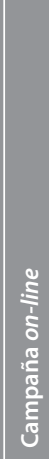 & 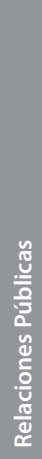 & 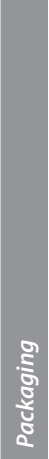 & 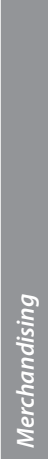 & 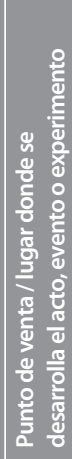 & 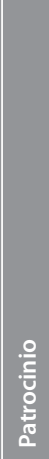 & 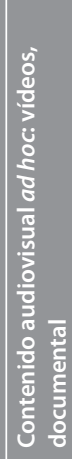 & 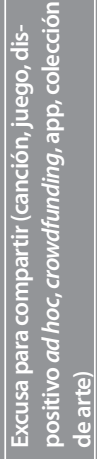 & के & $\begin{array}{l}\frac{\text { d }}{3} \\
\frac{2}{3} \\
\text { 은 }\end{array}$ & 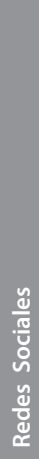 \\
\hline 21. The Other Side de Honda Motor Europa & & & & & & $x$ & & & & & & & & $x$ & $x$ \\
\hline 22. Made by You de Converse & & & $\mathrm{x}$ & & & & & & $\mathrm{x}$ & & & $\mathrm{x}$ & & & $x$ \\
\hline $\begin{array}{l}\text { 23. The Berlin Wall of Sound de } \\
\text { Soundcloud }\end{array}$ & & & & & & & & & & & & $\mathrm{x}$ & $\mathrm{x}$ & & \\
\hline 24. Radiant Return de PZ Cussons & $\mathrm{x}$ & $\mathrm{x}$ & & & & $\mathrm{x}$ & & & $\mathrm{x}$ & & $\mathrm{x}$ & & $\mathrm{x}$ & $\mathrm{x}$ & $x$ \\
\hline 25. Between Us de Vodafone & & & & & $x$ & $\mathrm{x}$ & & & $\mathrm{x}$ & & $x$ & $\mathrm{x}$ & & & \\
\hline $\begin{array}{l}\text { 26. Nazis against Nazis de ZDK } \\
\text { Gesellschaft Demokratische Kultur }\end{array}$ & & & & $x$ & & & & & & & $\mathrm{x}$ & & & $\mathrm{x}$ & $\mathrm{x}$ \\
\hline 27. House of Mamba de Nike & & & & & & & & & $\mathrm{x}$ & & $\mathrm{x}$ & & & & \\
\hline $\begin{array}{l}\text { 28. Holograms for Freedom de No } \\
\text { Somos Delito }\end{array}$ & & & & $x$ & & $\mathrm{x}$ & & & & & & & $\mathrm{x}$ & & $x$ \\
\hline $\begin{array}{l}\text { 29. The Marathon Walker de Water For } \\
\text { Africa }\end{array}$ & & & & & & $\mathrm{x}$ & & & $x$ & & & & & & \\
\hline 30. Proud Whopper de Burger King & & & & & & & $\mathrm{x}$ & & & & $\mathrm{x}$ & $\mathrm{x}$ & & $\mathrm{x}$ & $\mathrm{x}$ \\
\hline $\begin{array}{l}\text { 31. The Face of Litter de Hong Kong } \\
\text { Cleanup }\end{array}$ & & & & $\mathrm{x}$ & & $\mathrm{x}$ & & & & & $\mathrm{x}$ & & & & $\mathrm{x}$ \\
\hline $\begin{array}{l}\text { 32. } 805 \text { Million Names de United } \\
\text { Nations World Food Programme }\end{array}$ & & & & & $x$ & & $\mathrm{x}$ & & $\mathrm{x}$ & & $\mathrm{x}$ & & & & $\mathrm{x}$ \\
\hline 33. Reduce Speed Dial de Volkswagen & & & & & & & & & & & $x$ & $\mathrm{x}$ & & & \\
\hline 34. Elan Taste the Translation de Elan & & & & & & & & & $\mathrm{x}$ & & $\mathrm{x}$ & & & & \\
\hline 35. First Days Out de Mars Brasil & & & & & & $\mathrm{x}$ & & & & & $x$ & & & $\mathrm{x}$ & $\mathrm{x}$ \\
\hline $\begin{array}{l}\text { 36. Security Moms de Sport Clube do } \\
\text { Recife }\end{array}$ & & & & & & $x$ & & & $x$ & & $x$ & & & & \\
\hline $\begin{array}{l}\text { 37. The Gun Shop de States United To } \\
\text { Prevent Gun Violence }\end{array}$ & & & & & & $x$ & & & $\mathrm{x}$ & & $x$ & & & & \\
\hline
\end{tabular}


Gráfico 1 - Acciones más utilizadas en el Festival Cannes Lions en 2015, Titanium and Integrated

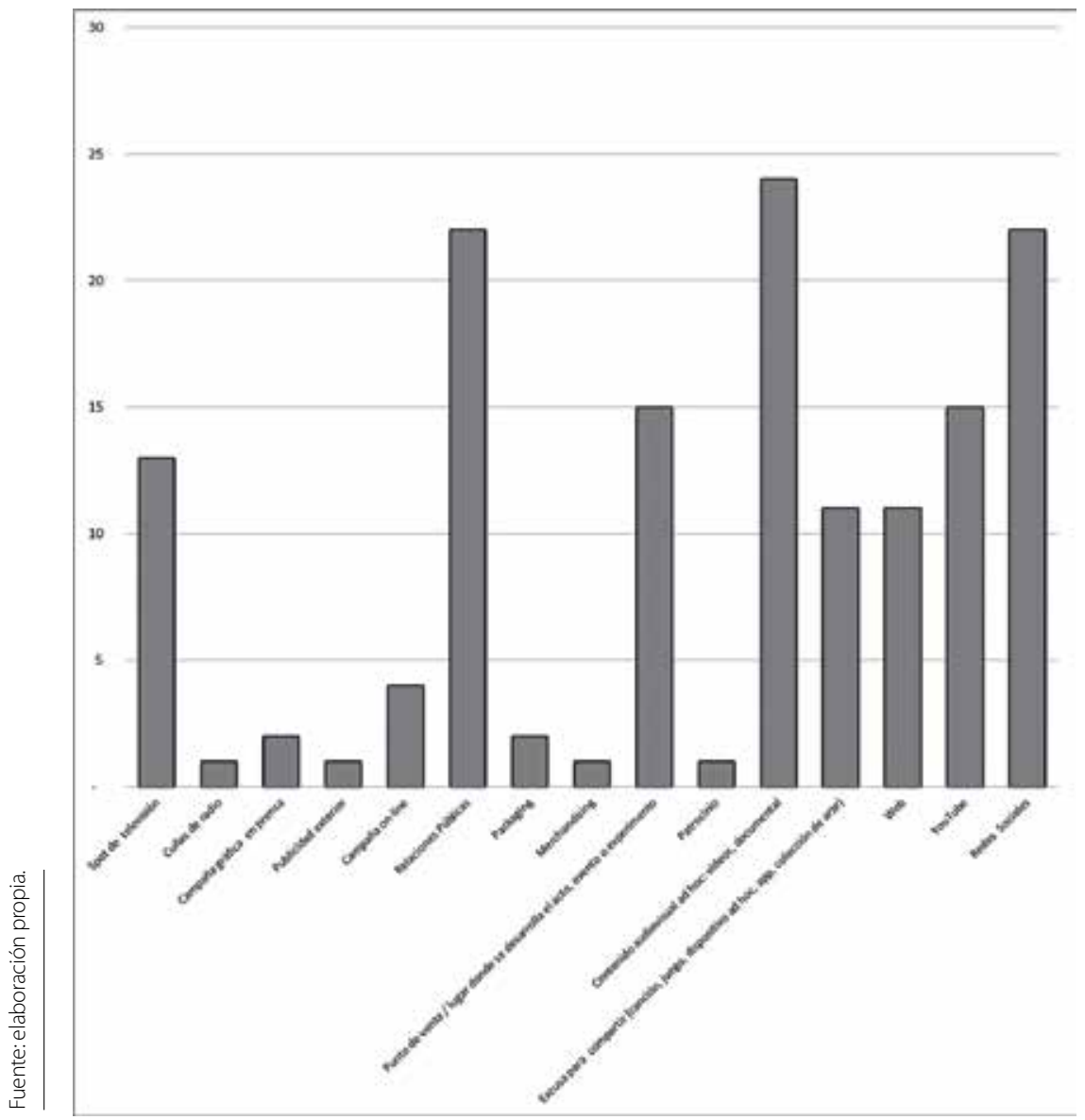

Gráfico 2 - Medios convencionales y no convencionales utilizados en el Festival Cannes Lions en 2015, Titanium and Integrated

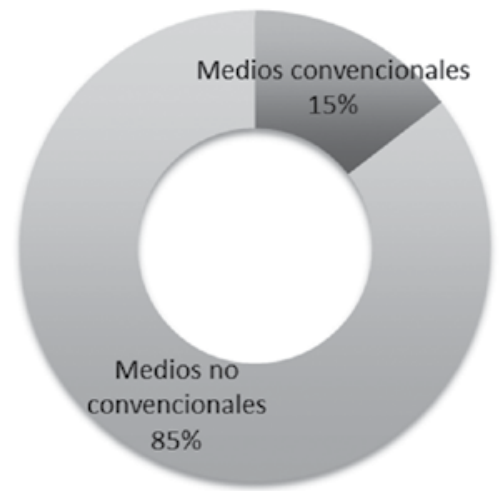


En cuanto a la distinción entre medios convencionales y no convencionales, destaca que el 85\% de las herramientas de comunicación utilizadas pertenece a medios no convencionales, mientras que un $15 \%$ se corresponde con medios convencionales. Es llamativa la diferencia entre ambos tipos de medios, y será conveniente estudiar si, en un futuro, se sigue dando tanto peso a los no convencionales.

\subsection{Comparación entre las campañas del Festival Cannes Lions 2015 y las del Festival El Sol de 2014}

Para poder verificar los objetivos planteados, se va a proceder a comparar los resultados cuantitativos de las campañas integradas del Festival El Sol 2014 y las del Festival Cannes Lions 2015. En primer lugar, se compararán los elementos utilizados, y en segundo lugar, el porcentaje de medios convencionales y no convencionales de un festival y de otro.

Como se ve en el gráfico, en ambos festivales las acciones más empleadas han sido spot, web, RR.PP., RR.SS. y YouTube. En cambio, las herramientas menos utilizadas en ambos casos fueron los patrocinios, la publicidad exterior, packaging y cuñas de radio. La diferencia entre ambos festivales reside en un mayor uso, en Cannes, de acciones en el punto de venta y sobre todo, del uso de contenido audiovisual ad hoc. Asimismo, identificamos un mayor empleo de herramientas más tradicionales en las campañas del Festival el Sol (TV, publicidad gráfica, RR.PP., merchandising), y por el contrario, el mayor uso de otras menos utilizadas históricamente, en el Festival de Cannes. Es decir, hay menos innovación en el entorno iberoamericano, que en el resto del mundo.

En ambos festivales el uso de medios no convencionales es mayor que la utilización de

\section{Gráfico 3 - Acciones más utilizadas en las campañas integradas de Cannes Lions 2015 y el Festival El Sol 2014}

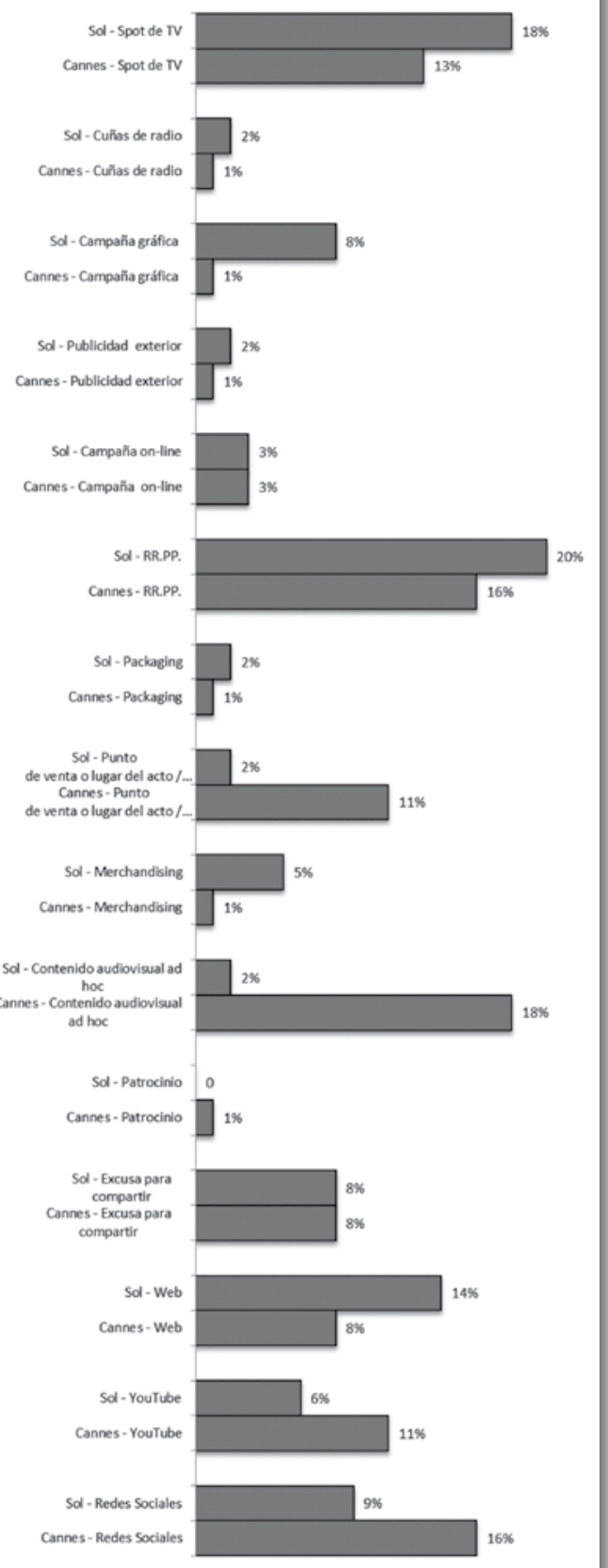

Fuente: elaboración propia. 


\section{Gráfico 4 - Comparación entre medios convencionales y no convencionales de Cannes Lions 2015 y el Festival El Sol 2014}

Sol - Medios convencionales

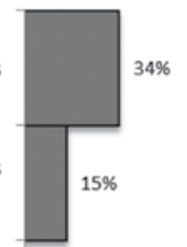

Sol - Medios no convencionales

Cannes - Medios no convencionales

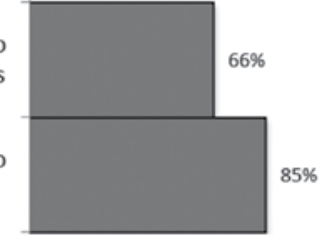

Fuente: elaboración propia.

medios convencionales, a la hora de plantear el mix de medios. Destaca Cannes sobre El Sol en el uso de medios no convencionales. De nuevo, encontramos menos innovación en el festival iberoamericano.

\subsection{Resultados del análisis cualitativo}

En el estudio cualitativo de las campañas, cabe destacar que las 37 campañas difieren mucho de ser tradicionales. 33 generan conversación, que está en la calle, en las redes sociales, y que posteriormente es recogida por otros medios de comunicación. Su contenido gira en torno a temas relacionados con una esfera cada vez más individualizada, como reconocimiento, seguridad, estereotipos, amistad, valentía, superación, etc.

El contenido de 22 de las campañas premiadas gira en torno a causas vinculadas al bien co- mún, aunque no sea el objeto a anunciar. Es decir, muchos productos realizan campañas relacionadas con una buena causa, para lograr notoriedad, y conexión con el público. 15 campañas trascienden en el tiempo, es decir, su validez va más allá del momento en el que se nos da a conocer. Se mantiene, en muchos casos, de manera indefinida para que su contenido siga vivo y deje poso en la sociedad. En 13, el protagonista de la campaña es la gente anónima que la ve, quien con sus reacciones la hacen posible, de forma que empoderan, indirectamente, al espectador. 12 pretenden emocionar o impresionar. 10 se basan en innovaciones tecnológicas. 6 van dirigidas a su público objetivo. 5 campañas cuentan con famosos para que el reconocimiento de lo anunciado sea mayor y más rápido. En otras 5 se hace una llamada al público para que interactuar con ellos. En 4 el protagonista del anuncio es una persona anónima, con quien el consumidor se identifica. El humor se emplea en 4 casos para llegar de forma más cercana al espectador. 3 campañas se realizan con un gran derroche técnico y de medios. Y en 2 se hace una notoria demostración de prueba de producto. En 1 se emplea metapublicidad. En el siguiente gráfico se resumen los principales resultados a nivel cualitativo. (Gráfico no ${ }^{5}$ ).

En relación con las campañas del anterior estudio, del Festival El Sol de 2014, observamos que varias cuestiones se repiten en el de Cannes. 1- Diferencias evidentes con las campañas tradicionales. 2-Trascendencia en el tiempo (duración indefinida, en muchos casos). 3-Vinculación al consumidor en la propia campaña, haciendo que sus reacciones constituyan la base de aquella. Aquel pasa de pasivo a activo; en él está puesta la atención, lo que aumenta la conexión y la identificación con la marca. El éxito de una campaña se basa en las reacciones de los 


\section{Gráfico 5 - Resultados del análisis cualitativo de las campañas del Festival Cannes Lions en 2015, Titanium and Integrated}

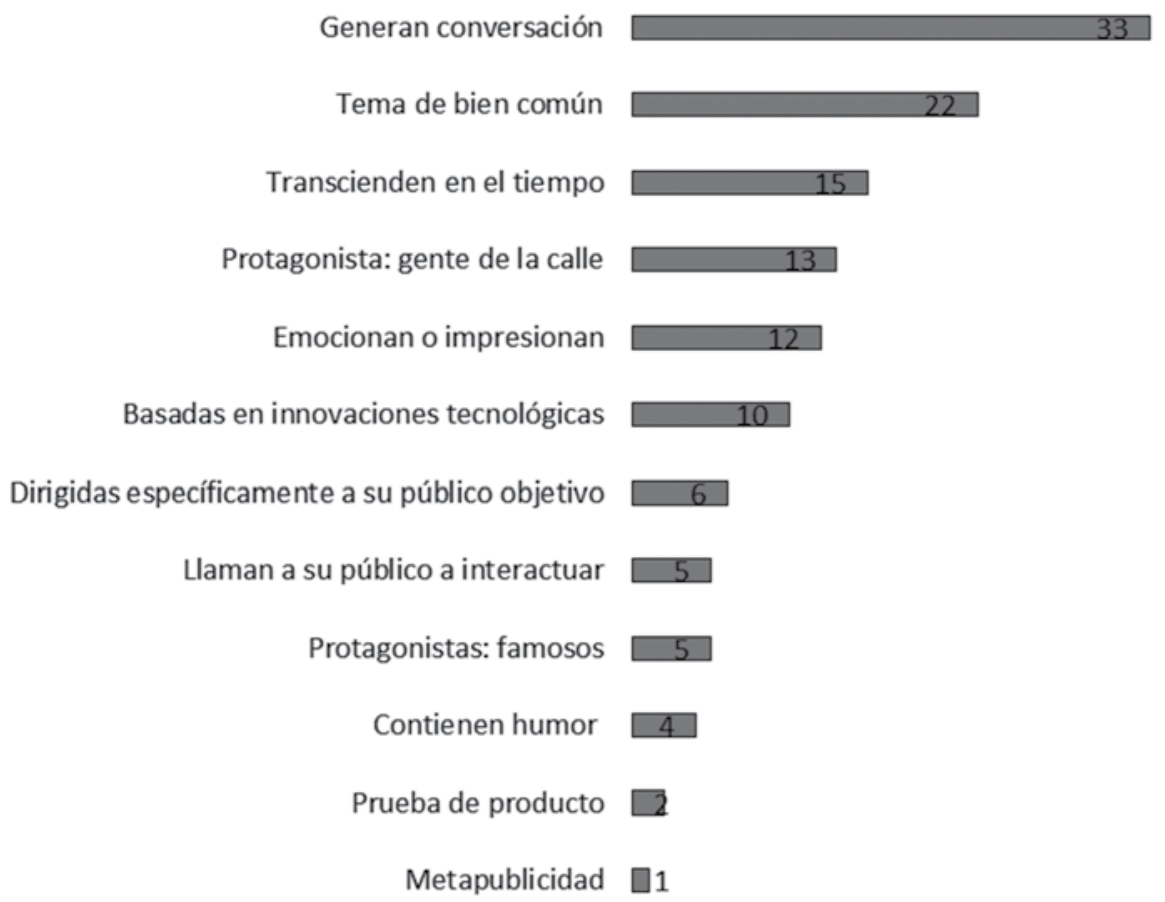

Fuente: elaboración propia.

consumidores y en la magnitud de su respuesta. Implicación, vinculación: efectividad. 4- Generación de conversación. En la calle, en RR.SS., y en los medios. 5- Búsqueda de relevancia de las marcas, para sus stakeholders.

Sobre la diferencia entre que la campaña llegue al consumidor y que el mensaje se quede en él (que cambie su posicionamiento, que compre, etc.), no existen datos exactos para medir la diferencia. En el caso de El Sol, algunas campañas llegaban, pero no cumplían su función empresarial (se quedaban solo en un logro comunicativo, sin anclaje con el objetivo).

\section{Discusión y conclusiones: ¿hacia} un nuevo modelo de comunicación?

En relación al objetivo propuesto para definir los elementos que caracterizan a las campañas integradas, el número de inscripciones en los festivales estudiados de campañas desarrolladas por las agencias para sus anunciantes, con acciones no convencionales, parece un indicador de estar ante ese posible nuevo modelo de comunicación. Fruto de la saturación publicitaria del consumidor, la aparición de nuevos soportes, o el auge de las plataformas de vídeo. Todo apunta a que se prefieren otro tipo de medios y es ahí 
donde debe estar la comunicación comercial. Dicho esto, a la hora de estudiar el objetivo de analizar los mecanismos de integración de diferentes áreas de marketing para la realización de las campañas, anunciantes y agencias no apuestan todo a una sola carta, sino que planifican estratégicamente medios, objetivos y resultados, para cumplir las expectativas de las partes implicadas. Estamos ante nueva manera de enfocar (sin restricciones) la comunicación, buscando notoriedad y conexión, algo que responde al objetivo relacionado con la implementación de nuevos elementos de comunicación para crear campañas atractivas para el consumidor. Pero hay que saber si esto es tendencia, moda o el inicio de éstas. También creemos que, como la labor de llegar al cliente es cada vez más compleja, es posible que se esté aplicando estrategias como la del del «Océano azul» (Kim y Mauborgne, 2015), la búsqueda de mercados en los que no haya competencia, llevada a la comunicación. Observamos que se están buscando espacios que la competencia no pueda usar, sin que parezca que va a la zaga; medios que se usen una sola vez, o que no sean replicables, para evitar que esos competidores puedan utilizarlos. Podríamos investigar más en este sentido, en campañas que respondieran a esta estrategia. ¿Y los medios tradicionales, visto lo visto, cambiarán su relación con la publicidad? Algo deberán hacer. ¿Tenderán a darnos mensajes con más contenido y menos comerciales? ¿Será, o es, Internet, el medio más adecuado para hacer publicidad? ¿El todo gratis, o el freemiun serán válidos? Y ya que hemos hecho un análisis internacional, se nos plantea la irremediable comparación con el caso español, nuestras empresas y su comunicación: menos innovadoras, y con menos conexión con el público, respecto a países como EE.UU. ¿Estaremos empezando a ir por esa línea? ¿Estarán pre- parados nuestros anunciantes y sus directivos, o seguirán pidiendo lo que siempre se ha hecho, instalados en una posible «zona de confort» tradicional, más aún con las incertidumbres de la crisis? ¿O en el otro extremo, proliferarán los que hemos dado en llamar «Generación 0»? Un público para el que la novedad es la meta, siendo indiferente si es positiva o negativa; sin espíritu crítico; simplemente apostando por la novedad, en sí misma. La idea del postmodernismo trasladado del arte a la vida, y de la vida a la comunicación.

Tras el análisis y comparación de las campañas integradas de ambos festivales, constatamos que los elementos más utilizados y que caracterizan a las campañas integradas, son: spots, web, RR.PP., RR.SS. y YouTube. Los medios no convencionales son las herramientas más empleadas para dar coherencia al mix de medios. A diferencia del Festival El Sol 2014, el uso de contenido audiovisual ad hoc destaca como el nuevo elemento de comunicación más atractivo de las campañas de Cannes. El pensamiento estratégico cada vez está más implantado, especialmente fuera de nuestro país, y la segmentación de públicos también crece. La publicidad se adapta cada vez más al consumidor. Se busca una comunicación más empática y anclada en la sociedad (Goleman, 2016). No se tiende a ir tanto a medios masivos, sino que también se utiliza comunicación de nichos. No se busca publicidad en sí, sino repercusión en RR.SS. y en otros medios. El consumidor se convierte en prescriptor. Según la investigación realizada, en España se innova menos que en Iberoamérica y en Iberoamérica menos que en el resto del mundo. En España es difícil que estas campañas se pidan, aprueben o entiendan, en caso de ser presentada a un anunciante. Encontramos así, grandes diferencias respecto a la mentalidad de algunos otros países. 
Creemos necesario investigar más sobre la efectividad, para diferenciar notoriedad y conexión, de resultados empresariales. En este sentido, podría ser bueno, seguir investigando en esta línea, comparando los resultados obtenidos, con un estudio similar de los «Premios a la eficacia», de la Asociación Española de Anunciantes, que se centran precisamente en valorar la eficacia de la acción comunicativa.

Observamos también la importancia de la creatividad enfocada a la relevancia. «Creativi- dad empresarial»: la que da relevancia social a una empresa, diferenciándola. Dentro de un mercado cada vez más maduro, los productos son casi iguales; las marcas podrían ser la clave para diferenciarlos (Aaker, 1996), no por productos o servicios sino por emotividad, practicidad, etc.; conceptos diferenciadores que puedan decantar a un consumidor hacia una empresa u otra. No en vano la publicidad nació (Eguizábal, 2011) para diferenciar y hacer atractiva la marca.

\section{Bibliografía}

Aaker, D. (1996). Construir marcas poderosas. Barcelona: Gestión 2000.

AAP. (2015, 30 de junio). Beer Tooth Implant. YouTube.

Disponible en: https://www.youtube.com/watch?v=wklHji $\mathrm{H} 5 \mathrm{MeI}$

Ad Council. (2015, 3 de marzo). Love Has No Labels. YouTube. Disponible en: https://www.youtube.com/watch?v= PnDgZuGIhHs

AdForum. (2015). Red Sox: Green Monster. AdForum. Disponible en: https://www.adforum.com/award-organization/ 6650183/showcase/2015/ad/34514692

Advert G. (2015, 22 de abril). Hong Kong clean up. The face of litter. YouTube. Disponible en: https://www.youtube. com/watch?v=gserVbhmqbs

Aguilera Moyano, J. de, Baños González, M. y Ramírez Perdiguero, F. J. (2016). Los Mensajes Hibridos en el marketing postmoderno: una propuesta de taxonomía. Icono 14, 14 (1), 26-57.

Always. (2015, 26 de junio). Always \#LikeAGirl. YouTube. Disponible en: https://www.youtube.com/watch?v=XjJ QBjWYDTs

Ambwani V.P., Heslop L., Dyke, L.S. (2011). Implementing diversity strategies: The challenges facing minority focused ad- vertising agencies. Equality, Diversity and Inclusion: An International Journal, 30 (4), 332-349.

Ampliffy Videos. (2014, 25 de julio). Radiant Return. YouTube. Disponible en: https://www.youtube.com/watch?v $=\mathrm{mk} 78 \mathrm{o}-\mathrm{SM} 4 \mathrm{ho}$

BBDO Group Germany. (2015, 25 de marzo). The monster smart launch. YouTube. Disponible en: https://www.youtube. com/watch?v=6B_awHyooos

Brand Buffet (2015b, 27 de junio). Monty's Christmas John Lewis Partnership. YouTube. Disponible en: https:// www.youtube.com/watch?v=TQ7yFmAMS-I

Brand Buffet. (2015a, 27 de junio). Emoji Ordering. YouTube. Disponible en: https://www.youtube.com/watch?v= NtdLsJsObrU

Brand Buffet. (2015c, 23 de junio). Vodafone red light application. YouTube. Disponible en: https://www.youtube. com/watch?v=PM8BbInoLec

Brand News (2015, 14 de julio). Allstate Insurance - Social Savvy Burglar. YouTube. Disponible en: https://www.youtube.com/watch?v=h55BkdlAbK0

Busch, O. (2014). Programmatic Advertising: The Successful Transformation to Automated, Data-Driven Marketing in RealTime. Hamburg: Spring. 
Cannes Lions. (2015). Titanium and Integrated. Cannes Lions. Disponible en: https://www.canneslions.com/cannes_ lions/awards/titanium_integrated/categories/

Carretero, M.J., Rangel, C. (2017). Comunicación estratégica integral frente a la publicidad tradicional. AdResearch, 15 (15), $32-53$.

Commercials HD: Abantec. (2015, 22 de abril). Made By You Converse All Star Commercial 2015. YouTube. Disponible en: https://www.youtube.com/watch?v=25fkGkMpbls

Cham Kim, W. Mauborgne, R. (2015). La estrategia del océano azul. Barcelona: Profit Editorial.

Damasio, A. (2010). Y el cerebro creó al hombre. Barcelona: Ediciones Destino.

David the Agency. (2015, 20 de febrero). Proud Whopper. Burger King US. YouTube. Disponible en: https://www.youtube.com/watch?v=KLaol_JA2uE

Digital Synopsis.com. (2015, 3 de marzo). Hearing Hands. Touching ad by Samsung. YouTube. Disponible en: https:// www.youtube.com/watch?v=UrvaSqN76h4

Eguizábal, R. (2011). Historia de la publicidad. Madrid: Editorial Fragua

El Sol Festival (2014). Campañas integradas e innovación. Festival El Sol. Disponible en: http://elsolfestival.com/palmares/edicion-2014/

Fmcomms (2015a, 28 de junio). Look At Me. YouTube. Disponible en: https://www.youtube.com/watch?v=Chu 7ILeYdxM Fmcomms (2015b, 28 de junio). Risk Everything. YouTube. Disponible en: https://www.youtube.com/watch?v= dAYcokreEZ8

Foot Locker (2015, 9 de octubre). Foot Locker x James Harden - Play My Tweet. YouTube. Disponible en: https://www. youtube.com/watch?v=pznnxBkyhdc

Goleman, D. (2016). Inteligencia emocional. Barcelona: Editorial Kairós

Grey Berlin. (2015, 22 de abril). SoundCloud - The Berlin Wall of Sound. YouTube. Disponible en: https://www.youtube.com/watch?v=3mUswgVQePU

J. Walter Thomson Amsterdam. (2015). ELAN Taste the translation. Vimeo. Disponible en: https://vimeo.com/120 790105

JWTMEA. (2015, 2 de julio). Abla Fahita, an entertainment brand. YouTube. Disponible en: https://www.youtube.com/ watch?v=_zsYrR-faGU
Levine, F, Locke, C., Searls, D., Weinberger, D. (1999). Manifiesto Cluetrain. Cambridge: Perseus Books.

MarketeerChannel. (2015, 23 de marzo). Nike. House of Mamba. YouTube. Disponible en: https://www.youtube. com/watch?v=-dt6AlrkiPk

Marketing Directo.com. (2013, 18 de abril). Gaby Castellanos: Me niego a mantener una agencia con clientes de calidad a costa de becarios. Marketing Directo. Disponible en: https://www.marketingdirecto.com/marketing-general/ agencias/gaby-castellanos-me-niego-a-mantener-una-agencia-con-clientes-de-calidad-a-costa-de-becarios

Martin, L. (2016). Small Data. España: Deusto.

Mayorga, S. (2016). Planificación estratégica, herramienta clave para la gestión de las marcas en el nuevo contexto publicitario. Contratexto, 25, 47-61.

MediaCat TV. (2015a). Cannes Lions 2015: Newcastle Band of Brands, Heinken USA. Vimeo. Disponible en: https://vimeo.com/132908921

MediaCat TV. (2015b). Cannes Lions 2015: Groceries Not Guns, Moms Demand Action For Gun Sense In America. Vimeo. Disponible en: https://vimeo.com/132442999

MediaCat TV. (2015b). Cannes Lions 2015: Newcastle Band of Brands, Heinken USA. Vimeo. Disponible en: https://vimeo.com/132908921

MediaCat TV. (2015c). Cannes Lions 2015: The Other Side, Honda Motor Europe . Vimeo. Disponible en: https://vimeo. com/132442999

Nosomos Delito. (2015, 24 de abril). Holograms for freedom. YouTube. Disponible en: e https://www.youtube.com/ watch?v=0jwmi6CguYO

Nyilasy, G., Reid, L. (2007). The academician-practitioner gap in advertising. International Journal of Advertising, 26 (4), $425-445$.

Ogilvy \& Mather Advertising Paris. (2015, 30 de junio). Water for Africa. The marathon walker. YouTube. Recuperado de https://www.youtube.com/watch?v=1v_06blcid4

Ogilvy Brazil. (2015, 24 de abril). Security Moms. YouTube. Disponible en: https://www.youtube.com/watch?v=LpK8B bwZOok

Pedigree (2015, 24 de abril). First Days Out. YouTube. Disponible en: https://www.youtube.com/watch?v=7KIYoe16 q9Q 
Prevent Gun Violence. (2015, 17 de marzo). Guns with History. YouTube. Disponible en: https://www.youtube.com/ watch?v=lnAfWfF4TjM

Rechts gegen Rechts. (2014, 17 de noviembre). «Nazis against Nazis. Germany's most involuntary charity walk. YouTube. Disponible en: https://www.youtube.com/watch?v= KvjIYl_Nlao StarterDaily. (2015, 27 de junio). Cannes Lions 2015 - Clever Buoy. YouTube. Disponible en: https://www.youtube. com/watch?v=9WgzgD3-dU0

Under Armour (2014, 4 de septiembre). Gisele Bündchen - I Will What I Want. YouTube. Disponible en: https://www. youtube.com/watch?v=H-V7cOestUs
Videos y Punto. (2015, 29 de julio). Nike RE2PECT Case Study. YouTube. Disponible en: https://www.youtube.com/ watch?v=q7DGWvrlU5A

Volkswagen New Zealand. (2015, 28 de abril). Reduce Speed Dial. YouTube. Disponible en: https://www.youtube.com/ watch?v=_gqN2n4VRzY

World Food Programme. (2015, 28 de abril). 805 million names. Zlatan Ibrahimovic YouTube. Disponible en: https:// www.youtube.com/watch?v=wDJjcL9Ya4c

Xfinity (2015, 20 de febrero). Emily's Oz. YouTube. Disponible en: https://www.youtube.com/watch?v=9jqRoFR5WHY 
